\title{
DESVINCULAÇÃO DE RECEITAS DOS ESTADOS (DRE): O CASO DAS EMPRESAS ESTATAIS
}

\section{DE-EARMARKING OF STATES REVENUES (DRE): THE CASE OF STATE-OWNED COMPANIES}

\author{
Vinícius Klein ${ }^{1}$ \\ Diogo Luiz Cordeiro Rodrigues ${ }^{1}$ \\ Igor Pires Gomes Costa ${ }^{1}$
}

\begin{abstract}
Recebido em: 23/11/2020 Aceito em: 10/11/2021

viniciusklein78@yahoo.com.br diogo.luiz.cordeiro@gmail.com igor_pires@hotmail.com
\end{abstract}

Resumo: As discussões envolvendo o alcance e os limites da desvinculação de receitas dos Estados (DRE), um importante instrumento de gestão fiscal, ganham uma especial relevância diante do argumento, desenvolvido por empresas estatais, no sentido de que o art. 76-A do ADCT não abarcaria as receitas por elas arrecadadas. Nesse contexto, com base em pesquisa legislativa e doutrinária, o presente artigo possui dois objetivos. Inicialmente, por meio de critérios de hermenêutica jurídica, o trabalho busca esclarecer a extensão do conceito de "receita corrente" empregado no dispositivo constitucional transitório, a fim de que se defina a possibilidade de incidência ou não da DRE sobre as receitas arrecadadas pelas empresas estatais, em especial as dependentes. Em seguida, o artigo analisa os impactos da DRE sobre a governança corporativa das empresas estatais como um todo, incluindo, assim, tanto empresas públicas quanto sociedades de economia mista, dependentes ou não. Ao final, o artigo conclui que, embora juridicamente possível no caso das empresas públicas dependentes, a incidência da DRE deve ser vedada no caso de estatais independentes e severamente mitigada em relação a sociedades de economia mista dependentes, em respeito aos princípios de governança corporativa previstos na legislação brasileira, especialmente accountability, transparência e ausência de conflitos de interesses.

Palavras-chave: Constituição de 1988, arts. 170 e 178. Fretamento. Lei 10.233, de 2001. Liberdade de iniciativa. Serviços de transporte.

\begin{abstract}
The debates on the scope and limits of the so-called De-earmarking of States Revenues (DRE), an important tool of fiscal management, gain special relevance due to the argument, built by state-owned companies, in the sense that art. 76-A of the ADCT would not affect the revenues collected by them. In such context, based on legislative and doctrinal research, this article has two objectives. Initially, this article builds on legal hermeneutics in order to clarify the concept of "current revenue" used by the transitional constitutional provision. In doing só, this work seeks to define the extent to which DRE could affect the revenues collected by state-owned companies, especially the dependent ones. Then, this article analyzes the impacts of DRE on the corporate governance of state-owned companies as a whole, thus including both public companies and mixed-capital companies, either dependent or not. In the end, this article concludes that, although legally possible in the case of dependent public companies, DRE should be prevented from affecting independent stateowned companies. This article also concludes that the application of DRE should be severely mitigated with regards to dependent mixed-capital companies, in accordance with the corporate governance principles provided for in Brazilian legislation, especially accountability, transparency and absence of conflicts of interest.
\end{abstract}

Keywords: Untying of State Revenues. State-Owned companies. Corporate governance. Financial Responsibility. Accountability.

\section{INTRODUÇÃO}

A Emenda Constitucional 93/2016 (BRASIL, 2016) estendeu a Estados e a Municípios o instituto da desvinculação de receitas, até então restrito à União. O embrião da técnica hoje conhecida como Desvinculação de Receitas da União (ou DRU) surgiu com a Emenda Constitucional

\footnotetext{
${ }^{1}$ Universidade Federal do Paraná - Paraná - Brasil
} 
de Revisão no 01/1994 (BRASIL, 1994), que instituiu o Fundo Social de Emergência (FSE), cujas finalidades declaradas resultavam na desvinculação irrestrita das receitas a ele aportadas, tudo em prol do "saneamento financeiro da Fazenda Pública Federal e de estabilização econômica", nos termos do art. 71, caput, do ADCT, com redação dada pela ER no 01/1994 (BRASIL, 1994; PINTO, 2008, p. 516).

Criada para ser uma ferramenta provisória de ajuste das contas públicas, a solução, no entanto, perenizou-se: em virtude das Emendas Constitucionais № 10/1996 e 17/1997, o FSE foi substituído pelo Fundo de Estabilização Fiscal (FEF) e, a partir do exercício financeiro de 2000, por força da Emenda no 27, o mecanismo foi rebatizado como Desvinculação de Receitas da União (DRU), já sem a roupagem (algo artificiosa) de fundo especial (BRASIL, 1996, 1997, 2000). Desde então, a DRU vem sendo sucessivamente reiterada, como revelam as Emendas Constitucionais 42/2003, 56/2007, 59/2009, 68/2011 (BRASIL, 2003, 2007, 2009, 2011), sem qualquer censura por parte do Supremo Tribunal Federal (RODRIGUES, 2017; BRASIL, 1996, 2009, 2010). O propósito básico de todas as versões da DRU consiste na autorização para que um certo percentual de receitas públicas normativamente vinculadas a finalidades específicas seja empregado em outras ações, a fim de que a gestão orçamentária não fique demasiadamente "engessada" (CONTI, 2018, p. 207/210), a deixando mais próxima de uma construção moderna e gerencial² ${ }^{2}$

A Emenda Constitucional № 93/2016 dá continuidade ao processo histórico iniciado com o FSE, aprofundando-o. Uma vez mais, o Constituinte derivado paga tributo à autonomia federativa de Estados, Distrito Federal e Municípios, estendendo-lhes pela primeira vez o mecanismo da desvinculação de receitas, ferramenta de gestão desejada há tempos por governadores e prefeitos, como expresso no voto do Deputado Laudívio Carvalho, relator da matéria na Comissão Especial que examinou a PEC no 014/2015, embrião da Emenda em questão (BRASIL, 2015).

As discussões envolvendo o alcance e limites da Desvinculação das Receitas dos Estados (DRE) ganham especial relevância quando analisadas sob o prisma das receitas arrecadadas pelas empresas estatais dependentes nos termos do art. 2ํㅗ III, da Lei Complementar 101/200, também conhecida como Lei de Responsabilidade Fiscal (BRASIL 2000). Segundo a classificação proposta por Weder de Oliveira (2015, p. 212) para as empresas estatais dependentes, o dispositivo legal destacado parece referir-se às estatais estruturalmente dependentes, isto é, aquelas empresas estatais "deficitárias por natureza"3.

Nada obstante o tratamento legal conferido a essas estatais, a salientar o laço de dependência que as une ao ente controlador, testemunha-se no cotidiano da administração pública a emergência de argumentos ou propostas, sobretudo por parte de gestores de estatais, que se apegam à autonomia formal dessas entidades da administração indireta com o objetivo de blindá-las contra a incidência do art. 76-A do ADCT, tendo em vista o atual cenário de escassez de recursos.

\footnotetext{
2 Para uma investigação detalhada acerca do percurso da administração pública indo da burocrática à gerencial ver: BOTELHO, Tiago Resende; HELD, Thaisa Maira. Da administração Pública Burocrática à Gerencial: o desafio da politização da burocracia no presidencialismo de coalizão. Revista do Direito, no 63, p. 163-185, 2021.

3 De acordo com o jurista, existem também as estatais contingencialmente dependentes, ou seja, aquelas "que, por razões conjunturais, necessitaram de aporte de recursos para cobertura de suas despesas de manutenção (despesas com pessoal e custeio)" (OLIVEIRA, 2015).
} 
Isso porque, segundo o dispositivo constitucional são desvinculadas as receitas de impostos, taxas, multas e outras receitas correntes.

Além da personalidade jurídica própria das entidades da administração indireta, que Ihes conferiria um grau de autonomia passível de invocação contra a DRE, essas propostas enfatizam que o art. 76-A do ADCT teria empregado a classificação de receitas correntes prevista no art. 11 da Lei $4.320 / 1964^{4}$.

De acordo com esse argumento, a DRE atingiria somente aquelas classificadas como "receitas tributárias" $\mathrm{e}$ "outras receitas correntes", permanecendo vinculadas, portanto, as demais receitas correntes, tais como as classificadas como "receitas agropecuárias", "receitas de serviços" e "receitas industriais", justamente aquelas arrecadadas por algumas estatais no exercício de seu objeto social. Em outras palavras: a DRE não atingiria receita provenientes, por exemplo, da produção de grãos, da prestação de serviços hospitalares ou de transporte, do desenvolvimento de tecnologias, entre outras atividades realizadas por empresas estatais ${ }^{6}$. Diante deste cenário, argumenta-se que a DRE, por se tratar de instrumento excepcional, atrairia também uma interpretação restritiva para o rol de receitas passíveis de desvinculação.

Em reação a essas propostas, contudo, poder-se-ia ressaltar não só o caráter de dependência de muitas dessas entidades da administração indireta (inclusive muitas empresas estatais), como também que o constituinte reformador teria empregado a expressão "outras receitas correntes" em sentido amplo, a incluir também as receitas de serviços e industriais apropriadas pelos entes da administração indireta.

Nesse contexto, o presente artigo propõe-se a investigar a extensão do conceito de "receita corrente" empregado no art. 76-A do ADCT, a fim de que se defina a incidência ou não da DRE sobre as receitas arrecadadas pelos entes da administração indireta, com ênfase nas empresas estatais dependentes e independentes, que são as entidades mais comumente associadas à percepção de receitas oriundas de atividades econômicas.

${ }^{4}$ Art. 11 - A receita classificar-se-á nas seguintes categorias econômicas: Receitas Correntes e Receitas de Capital.

$\S 1$ 1- São Receitas Correntes as receitas tributária, de contribuições, patrimonial, agropecuária, industrial, de serviços e outras e, ainda, as provenientes de recursos financeiros recebidos de outras pessoas de direito público ou privado, quando destinadas a atender despesas classificáveis em Despesas Correntes.

(...)

$\S 4^{\circ}$ - A classificação da receita obedecerá ao seguinte esquema:

RECEITAS CORRENTES

RECEITA TRIBUTÁRIA

Impostos.

Taxas.

Contribuições de Melhoria.

RECEITA DE CONTRIBUIÇÕES

RECEITA PATRIMONIAL

RECEITA AGROPECUÁRIA

RECEITA INDUSTRIAL

RECEITA DE SERVIÇOS

TRANSFERÊNCIAS CORRENTES

OUTRAS RECEITAS CORRENTES

${ }^{5}$ Acerca da relevância das receitas tributárias ver: FALCÃO, Maurin Almeida. O Paradoxo em torno do tributo como alicerce dos direitos à liberdade e à igualdade: uma relação ainda conturbada. Revista do Direito, no 60, p. 124-144, 2020.

${ }^{6}$ As receitas agropecuárias, industriais e de serviços são conceituadas pelo Manual de Contabilidade Aplicada ao Setor Público (MCASP) (BRASIL, 2019, p. 42/43). 


\section{DA APLICAÇÃO DA DRE}

Nesta seção será analisada aplicação da DRE as entidades autárquicas e empresas estatais, tendo-se em vista o alcance do art. 76-A do $\mathrm{ADCT}^{7}$, tanto em seu aspecto subjetivo (a quais sujeitos se aplica a DRE?) quanto em sua faceta objetiva (quais receitas são desvinculáveis?).

Pois bem. De acordo com uma interpretação possível, apoiada na condição de ente público personalizado e autônomo, defende-se que o rol de receitas desvinculáveis careceria de interpretação restritiva, dada a excepcionalidade da própria DRE. Assim, a expressão "outras receitas correntes" deveria ser lida em seu sentido técnico, nos termos da lista presente no art. 11 da Lei no 4.320/1964, permanecendo vinculadas as receitas industriais, agropecuárias e de serviços.

Uma segunda interpretação, por seu turno, defende que as empresas estatais dependentes e suas receitas estariam sujeitas ao campo de aplicação da DRE, seja em virtude da natureza jurídica, seja em razão do significado da expressão "outras receitas correntes", que não teria sido empregada em seu sentido técnico pelo Constituinte.

A inevitável interpretação do ordenamento jurídico pode ser feita pelos critérios gramatical, histórico, sistemático e teleológico, mas, como nos lembra Carvalho (2011, p. 49), necessariamente através das lentes da Constituição. Vale ressaltar que não há hierarquia entre os critérios de interpretação, que devem ser combinados no caso concreto, sempre em busca da solução constitucionalmente adequada.

O critério gramatical, também conhecido como literal, filológico, verbal ou semântico, é aquele pelo qual o intérprete busca atribuir significados aos enunciados linguísticos do texto legal ou constitucional, para daí extrair uma norma passível de aplicação, se for o caso (BARROSO, 1996, p. 119) ${ }^{8}$. No caso da interpretação constitucional, a doutrina mais autorizada prescreve que se deva privilegiar o sentido ordinário das palavras empregadas pelo constituinte, uma vez que a Constituição "não é uma norma técnica, voltada apenas aos profissionais da área jurídica, mas um texto que se destina a todo o povo, que deve ser partícipe do seu processo de interpretação" (SARMENTO, 2012, p. 411). A exceção fica por conta de situações em que resulte claramente do texto que o constituinte

\footnotetext{
${ }^{7}$ Art. 76-A. São desvinculados de órgão, fundo ou despesa, até 31 de dezembro de 2023, 30\% (trinta por cento) das receitas dos Estados e do Distrito Federal relativas a impostos, taxas e multas, já instituídos ou que vierem a ser criados até a referida data, seus adicionais e respectivos acréscimos legais, e outras receitas correntes. Parágrafo único. Excetuam-se da desvinculação de que trata o caput:

I - recursos destinados ao financiamento das ações e serviços públicos de saúde e à manutenção e desenvolvimento do ensino de que tratam, respectivamente, os incisos II e III do § 2 do art. 198 e o art. 212 da Constituição Federal;

II - receitas que pertencem aos Municípios decorrentes de transferências previstas na Constituição Federal;

III - receitas de contribuições previdenciárias e de assistência à saúde dos servidores;

IV - demais transferências obrigatórias e voluntárias entre entes da Federação com destinação especificada em lei;

V - fundos instituídos pelo Poder Judiciário, pelos Tribunais de Contas, pelo Ministério Público, pelas Defensorias Públicas e pelas Procuradorias-Gerais dos Estados e do Distrito Federal.

${ }^{8} \mathrm{O}$ texto, como se sabe, não se confunde com a norma, fruto do processo interpretativo. A norma, aliás, pode até mesmo dispensar suporte textual, caso das normas implícitas. (SARMENTO e SOUZA NETO, 2012, p. 410/411).
} 
quis referir-se ao seu sentido técnico-jurídico, como, por exemplo, nas normas que tratam do "direito adquirido", da "licitação" e do "imposto" (SARMENTO, op. cit., p. 412).

Do ponto de vista subjetivo (a quais sujeitos se aplica a DRE?), o caput do art. 76-A do ADCT indica serem desvinculadas certas receitas "de órgão, fundo ou despesa". Daí Conti e Carvalho (2017, p. 03) defenderem que a DRE não se estenderia a uma entidade personalizada como a Fundação de Amparo à Pesquisa do Estado de São Paulo (FAPESP), por exemplo.

No entanto, do ponto de vista meramente gramatical, viés interpretativo que estamos a enfatizar neste momento, o fato é que o texto do art. 76-A do ADCT, em seu caput, inclui expressamente não só os termos "órgão" e "fundo", mas também o vocábulo "despesa".

O conceito de "despesa pública", no contexto do direito financeiro nacional, encontra sua definição mais célebre na obra de Aliomar Baleeiro (1974, p. 81). Segundo o financista, a expressão pode abarcar dois sentidos, um global e outro concreto. Sob o prisma global, despesa pública seria o "conjunto dos dispêndios do Estado ou de outra pessoa de direito público, para o funcionamento dos serviços públicos". Em tal sentido, despesa pública seria o conjunto de gastos fixados no orçamento público anual, nos termos do art. 165, § 8oㅡㄹ da Constituição (BRASIL, 1988). Ademais, a locação "despesa pública" também pode designar "a aplicação de certa quantia, em dinheiro, por parte da autoridade ou agente público competente, dentro de uma autorização legislativa, para execução de fim a cargo do governo"' .

Desse modo, ainda que alguns entes da administração indireta não tenham natureza de órgão ou fundo, sujeitam-se em tese ao campo de incidência da DRE no tocante a suas despesas legalmente vinculadas, até porque esses gastos, como se sabe, competem com as demais necessidades coletivas expressas no orçamento público e geram reflexos em indicadores do Estado que ultrapassam em muito a situação individual da empresa, como "dívida pública, limites e condições para realização de operações de crédito, despesas com pessoal, receita corrente líquida, apuração de resultado primário", como explica Weder de Oliveira (2015, p. 212), Ministro-Substituto do Tribunal de Contas da União. Em outras palavras: as estatais dependentes integram o Erário para todos fins, razão pela qual devem participar do esforço fiscal do Estado, sem o qual nem sequer conseguiriam manter suas atividades.

Em relação ao aspecto objetivo da DRE ("quais são as receitas desvinculáveis?"), no caso do art. 76-A do ADCT, o texto constitucional revela intenção clara do legislador constituinte de situar o instituto em relação à classificação econômica das receitas públicas, que, como se sabe, podem ser "correntes" ou de "capital". A esse respeito, o Manual de Contabilidade aplicada ao Setor Público (BRASIL, 2019, p. 34) assim define as receitas correntes:

Receitas Orçamentárias Correntes são arrecadadas dentro do exercício financeiro, aumentam as disponibilidades financeiras do Estado e constituem instrumento para financiar os objetivos definidos nos programas e ações orçamentários, com vistas a satisfazer finalidades públicas.

\footnotetext{
${ }^{9}$ Os conceitos de Baleeiro são adotados pela maioria da doutrina financista. A título ilustrativo, v. Feijó, Carvalho Jr. e Ribeiro (2015, p. 201). Para uma visão crítica, v. Gomes (2015).
} 
As Receitas Orçamentárias de Capital servem aos mesmos propósitos. "Porém, de forma diversa das receitas correntes, as receitas de capital em geral não provocam efeito sobre o patrimônio líquido" (BRASIL, 2019, p. 34), que consiste, em linhas gerais, "na diferença, em determinado momento, entre o valor do ativo e do passivo, atribuindo-se a este último a conotação restritiva de dívidas e obrigações (IUDíCIBUS, 2015, p. 166/180).

É dizer: parece extreme de dúvidas que o constituinte, ao limitar a DRE às receitas correntes, desejou afastá-la das receitas de capital. Do texto, contudo, já não é possível extrair uma intenção clara de privilegiar a subclassificação específica das receitas correntes, tal como prevista no art. 11 da Lei 4.320/1964. E, como já visto, as definições técnicas devem ser prestigiadas no contexto da interpretação constitucional apenas na medida em que seja possível detectar manifesta intenção do constituinte de fazê-lo.

O critério histórico também não socorre os entes da administração indireta em sua interpretação restritiva.

Em síntese, seguindo Barroso (2010, p. 14), o critério histórico leva em conta a conjuntura específica em que se produziu a norma, os trabalhos legislativos e a intenção imediata do constituinte ou legislador, assim como a evolução legislativa anterior à elaboração da norma em si considerada, o ambiente social e as aspirações políticas da época ${ }^{10}$.

Nessa linha, rememore-se que a desvinculação constitucional de receitas foi projetada, desde o início, para ser um regime exorbitante em relação às normas gerais administrativas e financeiras, tudo em prol do "saneamento financeiro da Fazenda Pública Federal e de estabilização econômica", segundo o art. 71, caput, do ADCT, com redação dada pela Emenda Constitucional de Revisão no 01/1994 (BRASIL, 1994).

Tanto é assim que a ECR oํ 01/1994, responsável pela criação do Fundo Social de Emergência (FSE), precursor da Desvinculação de Receitas da União (DRU), incluiu receitas arrecadadas por autarquias e fundações ${ }^{11}$, também afastando explicitamente o disposto no art. 169 , $\S$ $9^{\circ}$, inc. II, da Constituição, segundo o qual cabe à Lei Complementar "estabelecer normas de gestão financeira e patrimonial da administração direta e indireta bem como condições para a instituição e funcionamento de fundos" (BRASIL, 1988)12. Desta forma, corroborando Scaff (2004, p. 37), afirma-se que as principais normas de direito financeiro deixaram de ser aplicadas à gestão do FSE.

Ora, a considerar esse lastro histórico, parece razoável concluir que a DRE, um instrumento exorbitante, não se deixaria limitar ou constranger por uma subclassificação da receita prevista na vetusta Lei ํㅜ 4.320/1964 e tampouco pela autonomia ordinária de empresas estatais dependentes equiparáveis a autarquias e fundações públicas integrantes do orçamento fiscal. Além disso,

\footnotetext{
${ }^{10}$ É o que Carlos Maximiliano denomina "occasio legis" (MAXIMILIANO, 1996, p. 148/150).

11 Confira-se a redação do art. 72, inc. I, do ADCT, conforme a ECR no 01/1994: "Art. 72. Integram o Fundo Social de Emergência: I - o produto da arrecadação do imposto sobre renda e proventos de qualquer natureza incidente na fonte sobre pagamentos efetuados, a qualquer título, pela União, inclusive suas autarquias e fundações;"

12 A exceção ao disposto no art. 169, § 9º, inc. II, da Constituição constava do art. 71, parágrafo único, do ADCT, incluído pela Emenda Constitucional de Revisão nº 001/1994.
} 
precisamos relembrar Sarmento e Souza Neto (2012, p. 39), no sentido em que as leis devem ser lidas à luz da Constituição e não o contrário ${ }^{13}$.

Do ponto de vista sistemático igualmente inexistem razões para o acolhimento da tese.

Por interpretação sistemática leia-se aquela que situa a norma jurídica em um espectro normativo mais amplo, é dizer, o ordenamento jurídico. Nesse contexto, a norma deve ser compreendida a partir de um todo coerente, que tem nos valores e princípios mais amplos seus critérios orientadores centrais (SARMENTO, 2012, p. 416). É a ideia de que "o Direito não se interpreta em tiras", na famosa expressão de Eros Grau (BRASIL, 2006, 2012).

Quanto à perspectiva subjetiva da querela, a respeito da incidência ou não da DRE sobre estatais dependentes, a jurisprudência do Supremo Tribunal Federal há muito firmou-se no sentido de que a autonomia de entidades autárquicas, em tudo semelhantes às estatais dependentes, não chega ao ponto de Ihes possibilitar primazia sobre normas constitucionais e legais ou sobre o poder de tutela garantido ao Estado. A título meramente ilustrativo, confira-se o precedente a seguir (BRASIL, 2006a):

\begin{abstract}
As universidades públicas são dotadas de autonomia suficiente para gerir seu pessoal, bem como o próprio patrimônio financeiro. O exercício desta autonomia não pode, contudo, sobrepor-se ao quanto dispõem a Constituição e as leis (art. 207 da CB/1988). Precedentes: RE 83.962, rel. min. Soares Muñoz, DJ de 17-4-1979, e ADI 1.599-MC, rel. min. Maurício Corrêa, DJ de 18-5-2001. As universidades públicas federais, entidades da administração indireta, são constituídas sob a forma de autarquias ou fundações públicas. Seus atos, além de sofrerem a fiscalização do TCU, submetem-se ao controle interno exercido pelo Ministério da Educação (MEC). Embora as universidades públicas federais não se encontrem subordinadas ao MEC, determinada relação jurídica as vincula ao Ministério, o que enseja o controle interno de alguns de seus atos (arts. $19 \mathrm{e}$ 25, I, do DL 200/1967). Os órgãos da administração pública não podem determinar a suspensão do pagamento de vantagem incorporada aos vencimentos de servidores quando protegido pelos efeitos da coisa julgada, ainda que contrária à jurisprudência. (...) Não há ilegalidade nem violação da autonomia financeira e administrativa, garantida pelo art. 207 da Constituição, no ato do ministro da Educação que, em observância aos preceitos legais, determina o reexame de decisão, de determinada universidade, que concedeu extensão administrativa de decisão judicial (arts. $1^{\circ}$ e $2^{\circ}$ do Decreto 73.529/1974, vigente à época). (RMS $22.047 \mathrm{AgR}$, rel. min. Eros Grau, j. 21-2-2006, 1르 T, DJ de 31-3-2006)
\end{abstract}

Por evidente, se a autonomia financeira das autarquias e entidades assemelhadas sujeita-se aos limites das normas legais e constitucionais, então parece defeso concluir que empresas públicas dependentes possuiriam lastro normativo bastante a impedir a desvinculação de receitas decorrente da Emenda Constitucional no 93/2016.

Já em relação às receitas desvinculáveis, como bem argumenta Feijó (2016), a interpretação restritiva, advogada pelas estatais dependentes, afastaria a DRE das contribuições, que a Lei no 4.320/1964 insere em uma categoria própria, inconfundível com a das "receitas tributárias" e a das

13 Em sentido complementar, Canotilho critica fortemente a proposta teórica, atribuída a Leisner, de que poderíamos chegar a significados constitucionais a partir do trabalho articulado pelo legislador infraconstitucional. Segundo o jurista lusitano, "teríamos, assim, a legalidade da constituição a sobrepor-se à constitucionalidade da lei”, o que é condenável. Cf. Canotilho (2002, p. 1219/1220). 
"outras receitas correntes". No entanto, se assim houvesse procedido o constituinte, não faria sentido a regra excepcional contida do art. 76-A, parágrafo único, inciso III, que se preocupa em vedar a incidência da DRE sobre as contribuições previdenciárias e de assistência à saúde dos servidores estaduais. Se assim o fez é porque outras contribuições eventualmente existentes deveriam, em tese, sofrer a desvinculação admitida no caput do art. 76- $\mathrm{A}^{14}$. Por via de consequência, também as receitas correntes arrecadadas pelos entes da administração indireta devem sujeitar-se à DRE.

Por fim, o critério teleológico, que outorga ao hermeneuta a tarefa de delimitar o alcance da norma a partir de sua finalidade precípua, igualmente não favorece a interpretação restritiva, seja em seu aspecto subjetivo, seja em sua faceta objetiva.

É que a finalidade básica da norma constitucional, à qual se deve sempre conferir eficácia máxima (SARMENTO e SOUZA NETO, 2012, p. 440), consiste justamente em aliviar o conhecido engessamento acarretado pelo sistema de vinculações ${ }^{15}$. Nessa linha, convém transcrever passagem do parecer elaborado pelo Deputado Laudívio Carvalho, relator da PEC nº 04/2015 da Câmara dos Deputados (BRASIL, 2015):

Se o expediente da vinculação é útil quando se toma cada área isoladamente, resta pouco produtivo na perspectiva do orçamento como um todo, criando barreira de difícil transposição para as autoridades da área econômica que têm a incumbência de conciliar o inconciliável: ajustar os gastos públicos e as demandas setoriais às restrições do orçamento. Assim, o ajuste fiscal acaba apoiando-se em novos aumentos da carga tributária, cujos espaços estão cada vez mais estreitos, ou se restringe a cortes das despesas consideradas flexíveis (discricionárias), em menor proporção na composição do orçamento, entre as quais os investimentos em infraestrutura.

A DRU contribui para ajustar a alocação dos recursos às restrições de caixa do Tesouro Nacional, ao aumentar os recursos ordinários (livres de vinculação) para o pagamento de despesas obrigatórias (gastos de pessoal e previdência) ou politicamente obrigatórias (bolsa-família e os benefícios de prestação continuada de assistência social), e, não menos importante, reduz a necessidade de emissão de novos títulos da dívida pública. Além do mais, o orçamento da União hospeda mais de 20 Fundos, com diferentes objetivos, alguns deles discutíveis, sendo que grande parte é protegida por recursos vinculados, seja por medida constitucional, seja por meio de norma legal.

A DRU permite que parte dos recursos destes Fundos seja realocada se for observado que há ineficiência em sua aplicação por parte da área beneficiada. Do ponto de vista da gestão do orçamento público, seja na União, ou nos Estados e Municípios, o excesso de vinculações na execução do orçamento contribui para a existência de um esforço fiscal assimétrico entre os diversos órgãos do governo, carência de recursos de um lado para execução de programas importantes, e desincentivos para a obtenção de qualidade e eficiência no gasto público pelos setores protegidos por algum

\footnotetext{
14 Nas palavras de Feijó (2016), "se a interpretação do caput fosse restritiva excluiria a incidência da DREM sobre todas as contribuições, o que tornaria descabido excluir, nos artigos 76-A, inciso III e art. 76-B, inciso II, as contribuições previdenciárias e de saúde. Assim, não precisaria o legislador excluir da desvinculação algo que já estaria fora do escopo no caput".

${ }^{15}$ Sobre o tema, em perspectiva crítica, ver: FREIRE JÚNIOR, Américo Bedê; DA SILVA Willy Potrich. Analítica e hermenêutica: duas faces de uma mesma solução para a garantia da racionalidade na aplicação do direito.
}

Revista do Direito, no 57, p. 43-62, 2019. 
tipo de vinculação. Tudo isto pode acabar representando uma pressão adicional para novas emissões de títulos da dívida pública.

Assim, na perspectiva da interpretação do texto normativo, a posição que encontra maior respaldo nos cânones hermenêuticos é a que permite a incidência da DRE sobre as receitas das autarquias e empresas estatais dependentes. Entretanto, esta posição deve ser sopesada quanto as suas consequências para a autonomia e a gestão destas entidades, em especial no caso das empresas estatais. Neste ponto, destaca-se, por exemplo, a possibilidade de uma sociedade de economia mista dependente ser afetada pela DRE. É a análise que será feita na próxima seção.

\section{DAS ESPECIFICIDADES DA APLICAÇÃO DA DRE EM RELAÇÃO ÀS DIVERSAS MODALIDADES DE EMPRESAS ESTATAIS}

O princípio da autonomia patrimonial pode ser visto um obstáculo significativo contra a incidência da DRE em relação às receitas correntes arrecadadas pelas estatais. Afinal, a personalização dessas entidades como empresas - ainda que estatais e dependentes - haveria de produzir algum efeito jurídico no tocante à gestão de seus recursos próprios. Nesse contexto, é possível imaginar que uma empresa sujeita à DRE terá que rever seu orçamento e até mesmo enfrentar dificuldades para manter em funcionamento a sua atividade empresarial. Sob tal perspectiva, ficariam prejudicados, não só o objeto social que fundamentou a criação da empresa, mas também a garantia patrimonial dos credores da empresa, bem como eventuais interesses de acionistas minoritários.

Inicialmente, cumpre salientar que a exploração direta de atividade econômica pelo Estado justifica-se apenas nas hipóteses do art. 173, caput, da Constituição, isto é, quando "necessária aos imperativos da segurança nacional ou a relevante interesse coletivo, conforme definidos em lei" (BRASIL, 1988). A exceção fica por conta de casos previstos na própria Constituição, como também esclarece 0 art. 173. Nesse contexto, confira-se o seguinte precedente do Superior Tribunal de Justiça (BRASIL, 2012):

(...) VII - As chamadas empresas estatais cumprem papel estratégico para o Estado (art. 174 da Constituição Federal). O Estado pode, por razões estratégicas, e com amparo legal, adotar decisões bem diferentes daquelas que um acionista privado faria, pois a existência desse tipo de companhia não visa somente o lucro e sim "...imperativos de segurança nacional ou a relevante interesse coletivo, conforme definidos em lei". Isso inclui aliená-las total ou parcialmente. (REsp 745.739/RJ, Rel. Massami Uyeda, Terceira Turma, DJe 21/09/2012).

Assim, pode-se afirmar que as empresas estatais não podem ser criadas apenas para obtenção de lucro - mesmo sendo a lucratividade natural para qualquer empresa, inclusive a estatal , mas seu objeto social deve estar justificado por um dos permissivos constitucionais. Portanto, a execução do seu objeto social de forma adequada representa não apenas uma condição para a sua lucratividade, mas também a concretização do interesse público subjacente a sua criação. Deste 
modo, a proteção contra interferências na sua autonomia patrimonial e, por conseguinte, a execução do seu objeto social é constitucionalmente relevante. Esse raciocínio permanece válido mesmo em sociedades de sociedades de economia mista, que de apesar possuírem acionistas privados tem a execução do seu objeto social e na sua governança necessariamente a concretização de relevante interesse coletivo ou imperativo de segurança nacional.

Aqui, convém retomar a distinção entre estatais dependentes e não dependentes, já que, no primeiro caso, a ingerência do Estado sobre as atividades da empresa é mais forte. Embora a persecução do interesse público subjacente a sua criação seja obrigatória para qualquer modalidade de empresa estatal ${ }^{16}$, o fato é que estatais não dependentes, cujas atividades sejam realizadas sem aportes do Estado para cobertura de gastos correntes ou de capital, o controle estatal na gestão de seus recursos é menor, e qualquer intervenção pode colocar em risco o sucesso empresarial propriamente dito e criar uma situação de dependência. Em contrapartida, tais empresas não devem receber qualquer forma de tratamento diferenciado, já que tal expediente poderiam resultar em ofensa ao princípio constitucional da livre concorrência (JUSTEN FILHO, 2016, p. 139/140).

Entretanto, algumas empresas por uma questão conjuntural ou estrutural passam a ser classificadas como dependentes, já que passam a depender de recursos estatais para os seus gastos de custeio. Seu caráter deficitário pode decorrer de uma crise conjuntural do mercado, de uma mudança regulatória ou institucional que afeta a sua atividade ou mesmo de problemas de gestão. Ora, quando a continuidade dessas empresas reclama aportes continuados por parte do Estado, é natural que as receitas próprias dessas entidades não estejam inteiramente a sua disposição, até porque, como já dito anteriormente, o desempenho das estatais dependentes afeta diretamente a gestão fiscal do Estado (o que não ocorre com as estatais não dependentes). Quanto aos credores, não há prejuízo: há muito a jurisprudência fixou-se no sentido de que o Estado é responsável subsidiariamente pelo cumprimento de obrigações ou pelo ressarcimento de danos que a empresa estatal não tenha condições de suportar (BRASIL, 2007). Nessa linha, confira-se o precedente a seguir:

\begin{abstract}
ADMINISTRATIVO. RECURSO ESPECIAL. RESPONSABILIDADE CIVIL RESPONSABILIDADE OBJETIVA. RESPONSABILIDADE SUBSIDIÁRIA DO ESTADO. 1. As regras de Direito Administrativo e Constitucional dispõem que as empresas criadas pelo Governo respondem por danos segundo as regras da responsabilidade objetiva, e, na hipótese de exaurimento dos recursos da prestadora de serviços, o Estado responde subsidiariamente (art. 37, § 6º, da Constituição Federal). (...) 3. Recurso especial provido. (REsp 738.026/RJ, Rel. Ministra ELIANA CALMON, Rel. p/ Acórdão Ministro JOÃO OTÁVIO DE NORONHA, SEGUNDA TURMA, julgado em $26 / 06 / 2007$, DJ 22/08/2007, p. 452)
\end{abstract}

\footnotetext{
${ }^{16}$ Em sentido aproximado, cf. Pinto (2010, p. 229). Atualmente, a satisfação de interesse público por parte das estatais também está prevista no art. $2^{\circ}$, $\S 1^{\circ}$, da Lei 13.303/2016, dispositivo que inclui qualquer modalidade de empresa estatal: "Art. $2^{\circ} \mathrm{A}$ exploração de atividade econômica pelo Estado será exercida por meio de empresa pública, de sociedade de economia mista e de suas subsidiárias. § 1ำ A constituição de empresa pública ou de sociedade de economia mista dependerá de prévia autorização legal que indique, de forma clara, relevante interesse coletivo ou imperativo de segurança nacional, nos termos do caput do art. 173 da Constituição Federal." (BRASIL, 2016)
} 
A questão fica mais complexa quando se observa que a situação fática de dependência ou independência pode ocorrer tanto em empresas públicas quanto em sociedades de economia mista, sendo que as últimas se caracterizam pela presença de acionistas minoritários privados. Neste contexto, a DRE possivelmente influenciaria de maneira negativa o resultado da empresa, prejudicando a distribuição de dividendos, por exemplo. Além disso, existe a possibilidade de que a desvinculação possa caracterizar-se como abuso do poder do acionista controlador, figura prevista no art. 117 da Lei 6.404/1976, também conhecida como Lei das Sociedades Anônimas (BRASIL, 1976), e endossada pelo art. 15 da Lei oㅜ 13.303/2016 (ou Lei das Estatais) (BRASIL, 2016), que se refere a condutas intencionalmente praticadas pelo controlador no âmbito societário. Apesar de ser possível fazer interpretação diversa tendo-se como base os art. $\S 2^{\circ}$ do artigo $1^{\circ}$ da Lei das Estatais ${ }^{17}$ a leitura mais adequada é a que aplica o conceito de abuso do controlador também às estatais dependentes, uma vez que a aplicação decorre da própria Lei das Sociedades Anônimas, norma a qual as companhias estão sujeitas independentemente da situação de dependência. Ademais, as práticas de governança corporativa que fundamentam a Lei das Estatais se aplicam a qualquer companhia (KLEIN e GRANDO, 2019, p. 31-46), não havendo razão para exclusão apenas pela classificação da empresa estatal como dependente.

Aqui deve-se observar uma peculiaridade adicional da situação. Apesar da DRE não depender de qualquer decisão por parte do ente controlador, a Administração Pública na posição de controlador terá que se manifestar nos órgãos societários pertinentes, por exemplo na hipótese de cancelamento de investimentos já devidamente autorizados ou redução dos dividendos anunciados ou mesmo em deliberação acerca da estratégia para questionamento pela companhia da aplicação da DRE. Portanto, mesmo que 0 ato administrativo aplicando a DRE seja autorizado constitucionalmente e desvinculado dos espaços societários, pode-se chegar a um paradoxo: a adoção da DRE nas empresas estatais configurar um ato de abuso do controlador.

A possibilidade de prejuízo a acionistas minoritários aumenta a sensibilidade da aplicação da DRE nas empresas estatais. Neste ponto deve-se observar que a Lei das Estatais impôs a adoção de um conjunto de práticas de governança corporativa, que em última análise visam à proteção do acionista minoritário, o que inclui tanto os acionistas privados nas sociedades de economia mista quanto os minoritários de outra entidade federativa, por exemplo em uma empresa controlada pela União mas com participações acionárias minoritárias dos Estados ou Municípios. Afinal, quando se trata da proteção aos acionistas minoritários estão incluídos tantos os com natureza de direito privado como de direito público. As normas de governança corporativa, mencionadas expressamente na exposição de motivos da Lei das Estatais, além de princípios gerais como transparência, responsabilidade corporativa, prestação de contas (accountability) e equidade trazem práticas específicas de governança, sendo que algumas tonaram-se obrigatórias com a referida norma legal para as empresas estatais. A imposição destas normas de governança nas empresas estatais é conhecida pela expressão corporatização e existem estudos que apontam ganhos significativos em

17 Lei $13.303 / 2016$. "Art. $1^{\circ}(\ldots) \S 2^{\circ} \mathrm{O}$ disposto nos Capítulos I e II do Título II desta Lei aplica-se inclusive à empresa pública dependente, definida nos termos do inciso III do art. $2^{\circ}$ da Lei Complementar no 101 , de 4 de maio de 2000 , que explore atividade econômica, ainda que a atividade econômica esteja sujeita ao regime de monopólio da União ou seja de prestação de serviços públicos." 
termos de valor e eficiência da companhia (LAZZARINI \& MUSACHIO, 2015, p. 197-225). Para fins deste estudo, pode-se destacar neste aspecto os documentos indicados no seu artigo $8^{\circ}$ da Lei das Estatais (BRASIL, 2016), tais como uma política de distribuição de dividendos e uma carta anual de governança e de aderência a políticas pública. Ainda, afirma o referido artigo que quaisquer obrigações e responsabilidade que a empresa estatal possua e não seja extensível às empresas privadas devem estar claramente definidas em termos de receitas e custos sujeitos a ampla publicidade. Esses instrumentos concretizam um dos princípios basilares da gestão corporativa que é a transparência e visam a evitar que os acionistas minoritários sejam surpreendidos por medidas que produzam benefícios privados para o controlador.

Assim, a aplicação da DRE no contexto do esforço fiscal da Administração Pública de forma unilateral e sem respeito às práticas de governança das companhias, além do abuso do poder de controle pode resultar em consequências negativas para a própria execução do objeto social, tanto pela perda de valor de mercado em função da interferência indevida do controlador, quanto pela dificuldade de atrair recursos nos mercados de capitais e financeiro. Afinal, a perda abrupta de receita pode significar um risco maior de inadimplência e um acesso menor ou mais custoso a fontes de financiamento da companhia, dentre outros efeitos.

Neste contexto, pode-se afirmar que a grande dificuldade na aplicação da DRE diz respeito às empresas estatais dependentes que adotam a forma de sociedade de economia mista. Nestes casos, a aplicação dever ser evitada pelos prejuízos concretos trazidos a gestão da companhia e a execução do seu objeto social, que é em última análise, uma forma de concretização de relevante interesse coletivo ou um imperativo de segurança nacional. Agora, caso se torne necessária a aplicação da DRE em um contexto de esforço fiscal ela deve ser aplicada de forma a que as perdas de accountability ${ }^{18} \mathrm{e}$ transparência da administração da companhia sejam minoradas. O que significa condicionar a aplicação da DRE a menção expressa nos documentos indicados no art. $8^{\circ}$ da Lei das Estatais, em especial na carta de políticas públicas e governança corporativa, de forma a evitar que os acionistas minoritários sejam surpreendidos e tenham expectativas legítimas desfeitas. Outro ponto relevante é o respeito à política de longo prazo de distribuição de dividendos. Afinal, a aplicação da DRE em desacordo com os documentos do art. 8ำ da Lei das Estatais pode caracterizar o já mencionado abuso do controlador. Ainda, a divulgação para o mercado deve ser feita de forma adequada. Já nas deliberações em Assembleia e reuniões de Conselho de Administração que tratem da aplicação e das consequências da DRE, os representantes do controlador devem sempre que necessário indicar a situação de conflito de interesse e deixar de se manifestar. Por fim, deve haver a respeito a todas as normas do mercado de capitais, em especial quanto a divulgação de informações e procedimentos de governança, que são aplicáveis a quaisquer empresas que atuam no mercado de capitais, independentemente da natureza pública ou privada do controle.

Deste modo, pode-se afirmar que a interpretação que melhor conjuga o texto da DRE com a Lei das Estatais é aquela que permite a sua aplicação às empresas estatais dependentes, mas respeitando-se os instrumentos de governança corporativa e o direito dos minoritários no caso das

${ }_{18}$ Para os fins deste trabalho, accountability significa o dever de prestação de contas e eventual responsabilização do administrador perante os órgãos diretivos e acionistas da entidade. Sobre o tema, cf., por exemplo, Pinho e Sacramento (2009). 
sociedades de economia mista, de modo que não seja permitida a frustação das expectativas legítimas dos acionistas minoritários. Assim, a aplicação da DRE para empresas estatais dependentes que adotem a forma de sociedade de economia mista deve ser cercada de cuidados adicionais, de forma a se minimizar eventuais prejuízos à execução do objeto social e à governança da companhia, em especial a accountability, e a transparência da gestão e a ausência de conflitos de interesse.

\section{CONSIDERAÇÕES FINAIS}

Assim, a extensão da DRE de forma a englobar as entidades autárquicas e empresas pode ser justificada pela interpretação da expressão receitas correntes constante do art. 76-A do ADCT, uma vez que a aplicação dos critérios gramatical, histórico, sistemático e teleológico apontam neste sentido. A solução apontada, entretanto, não está isenta de dificuldades, em especial nas empresas estatais não dependentes (ou independentes). Quanto às empresas estatais independentes, a aplicação da DRE não é possível, uma vez que os seus recursos não fazem parte do esforço fiscal e a imposição da DRE, além do desrespeito a sua personificação jurídica, coloca em risco a concretização do seu objeto social. Esse raciocínio é válido tanto para as empresas estatais independentes que adotem a forma de empresa pública quanto aqueles que, por possuírem acionistas minoritários privados, são consideradas sociedades de economia mista.

Já no caso das empresas estatais dependentes, a participação no esforço fiscal é a regra e, portanto, a aplicação da DRE não gera a mesma dificuldade, resguardados aspectos básicos de governança corporativa ditados pela Lei das Estatais. Aqui, a aplicaçãoda DRE justifica-se por que o financiamento das despesas de custeio pelo ente controlador necessariamente afasta a autonomia patrimonial e a personificação jurídica da estatal. A problemática mais delicada surge no caso das estatais dependentes que adotam a forma societária de sociedade de economia mista. Neste caso, a aplicação da DRE pode gerar abuso de poder do controlador e produzir uma expropriação de riqueza dos minoritários, precisamente o que buscam evitar as normas de governança corporativa presentes na Lei das Estatais, que tratam da forma de exercício do poder de decisão dentro da companhia (MOORE \& PETRIN, 2017, p. 3-22). Neste sentido, a aplicação da DRE deve ser feita de forma a minorar os prejuízos à gestão da companhia, em especial a accountability e a transparência da gestão. Nesse sentido a DRE somente deve ser aplicada se compatível com os instrumentos de gestão indicados no art. $8^{\circ}$ da Lei das Estatais, em especial a carta de políticas públicas e governança e a política de dividendos. Ainda, todos os procedimentos de disclousure e apresentação de informações ao mercado devem ser seguidos, em especial no caso de empresas estatais com ações em bolsa de valores. Por fim, a votação nos órgãos societários derivadas da aplicação da DRE devem ser feitas sempre com a observância da ausência de conflito de interesses dos representantes dos acionistas controlador. Portanto, observa-se que apesar de possível a aplicação da DRE nas empresas estatais dependentes que adotam a forma de sociedade de economia mista, mas ela deve ser cercada de cuidados de forma a que a sua aplicação não seja feita de forma a não caracterizar um ato de abuso do controlador. 


\section{REFERÊNCIAS}

BALEEIRO, Aliomar. Uma Introdução à Ciência das Finanças. 10ª ed. Rio de Janeiro: Forense, 1974.

BARROSO, Luís Roberto. Interpretação e aplicação da Constituição. São Paulo: Saraiva, 1996. Federalismo, isonomia e segurança jurídica: inconstitucionalidade das alterações

na distribuição de royalties do petróleo. Consulta formulada pelo Estado do Rio de Janeiro.

Universidade do Estado do Rio de Janeiro, 2010.

BOTELHO, Tiago Resende; HELD, Thaisa Maira. Da administração Pública Burocrática à Gerencial: o desafio da politização da burocracia no presidencialismo de coalizão. Revista do Direito, no 63, p. 163-185, 2021.

BRASIL. Ministério da Fazenda. Secretaria do Tesouro Nacional. Manual de Contabilidade Aplicada ao Setor Público (MCASP). 8ª ed. Brasília, DF, 2019. Disponível em $<$ http://www.tesouro.fazenda.gov.br/documents/10180/695350/CPU MCASP+8\%C2\%AA\%20ed++publica\%C3\%A7\%C3\%A3o com+capa 3vs Errata1/6bb7de01-39b4-4e79-b909-6b7a8197afc9> (Acesso em 01/05/2020)

. Câmara dos Deputados. Proposta de Emenda Constitucional (PEC) no 04/2015. Brasília, DF, 2015. Disponível em $<$ http://www.camara.gov.br/proposicoesWeb/prop mostrarintegra?codteor=1460670\&filename=PRL+ $1+P E C 00415+\% 3 D \% 3 E+P E C+4 / 2015>$ (Acesso em 01/05/2020)

. Constituição da República Federativa do Brasil de 05 de outubro de 1988. Brasília, DF, 1988. Disponível em <http://www.planalto.gov.br/ccivil 03/constituicao/constituicao.htm> (Acesso em 01/05/2020)

Emenda Constitucional de Revisão 01, de 1ํ de março de 1994. Brasília, DF, 1994. Disponível em <http://www.planalto.gov.br/ccivil 03/constituicao/Emendas/ECR/ecr1.htm>. (Acesso em 01/05/2020)

Emenda Constitucional 10, de 4 de março de 1996. Brasília, DF, 1996. Disponível em $<$ http://www.planalto.gov.br/ccivil 03/constituicao/Emendas/Emc/emc10.htm>. (Acesso em 01/05/2020)

Emenda Constitucional 17, de 22 de novembro de 1997. Brasília, DF, 1997. Disponível em $<$ http://www.planalto.gov.br/ccivil 03/constituicao/Emendas/Emc/emc17.htm>. (Acesso em 01/05/2020)

. Emenda Constitucional 27, de 21 de março de 2000. Brasília, DF, 2000. Disponível em $<$ http://www.planalto.gov.br/ccivil 03/constituicao/Emendas/Emc/emc27.htm>. (Acesso em 01/05/2020)

Emenda Constitucional 42, de 19 de dezembro de 2003. Brasília, DF, 2003. Disponível em $<$ http://www.planalto.gov.br/ccivil 03/constituicao/Emendas/Emc/emc42.htm>. (Acesso em 01/05/2020) 
Emenda Constitucional 56, de 20 de dezembro de 2007. Brasília, DF, 2007. Disponível em $<$ http://www.planalto.gov.br/ccivil 03/constituicao/Emendas/Emc/emc56.htm>. (Acesso em 01/05/2020)

Emenda Constitucional 59, de 11 de novembro de 2009. Brasília, DF, 2009. Disponível em $<$ http://www.planalto.gov.br/ccivil 03/constituicao/emendas/emc/emc59.htm>. (Acesso em 01/05/2020)

Emenda Constitucional 68, de 21 de dezembro de 2011. Brasília, DF, 2011. Disponível em $<$ http://www.planalto.gov.br/ccivil 03/constituicao/Emendas/Emc/emc68.htm>. (Acesso em 01/05/2020)

Emenda Constitucional 93, de 08 de setembro de 2016. Brasília, DF, 2016. Disponível em $<$ http://www.planalto.gov.br/ccivil 03/constituicao/Emendas/Emc/emc93.htm >. (Acesso em 01/05/2020)

Supremo Tribunal Federal. ADI 1420-MC, rel. Min. Néri da Silveira, Brasília, DF, 1996, DJ 17.05.1996.

ADI 3.685, rel. Min. Ellen Gracie, Brasília, DF, 2006, DJ 10.08.2006.

RMS 22.047 AgR, rel. min. Eros Grau, Brasília, DF, 2006, DJ de 31.03.2006.

RE 537.610, rel. Min. Cezar Peluso, Brasília, DF, 2009, DJe 17.12.2009.

RE 614.184, rel. Min. Cármen Lúcia, Brasília, DF, 2010, DJ 15.06.2010.

ADPF 101, rel. Min. Cármen Lúcia, Brasília, DF, 2012, DJ 04.06.2012.

Superior Tribunal de Justiça. REsp 738.026, Rel. Min. Eliana Calmon, Rel. p/ Acórdão Ministro João Otávio de Noronha, Segunda Turma, Brasília, DF, DJ 22/08/2007.

REsp 745.739, Rel. Massami Uyeda, Terceira Turma, Brasília, DF, 2012, DJe 21/09/2012.

Lei 4.320, de 17 de março de 1964. Brasília, DF, 1964. Disponível em $<$ http://www.planalto.gov.br/ccivil 03/leis//4320.htm>. (Acesso em 01/05/2020)

. Lei 6.404, de 15 de dezembro de 1976. Brasília, DF, 1976. Disponível em <http://www.planalto.gov.br/ccivil 03/leis/l6404consol.htm>. (Acesso em 01/05/2020)

. Lei Complementar 101, de 04 de maio de 2000. Brasília, DF, 2000. Disponível em $<$ http://www.planalto.gov.br/ccivil 03/leis/lcp/lcp101.htm >. (Acesso em 01/05/2020)

Lei 13.303, de 30 de junho de 2016. Brasília, DF, 2000. Disponível em <http://www.planalto.gov.br/ccivil 03/ ato2015-2018/2016/lei//13303.htm>. (Acesso em 01/05/2020) CANOTILHO, José Joaquim Gomes. Direito Constitucional e Teoria da Constituição, 6ª ed. Coimbra: Almedina, 2002.

\section{CARVALHO, André Castro. Direito Constitucional Financeiro e Direito Orçamentário}

Substantivo. In: CONTI, José Mauricio; SCAFF, Fernando Facury (coords.) Orçamentos Públicos e Direito Financeiro. São Paulo Ed. Revista dos Tribunais, 2011.

CONTI, José Mauricio. Levando o direito financeiro a sério: a luta continua. $3^{a}$ ed. São Paulo: Blucher, 2018. 
CONTI, José Mauricio; CARVALHO, André Castro. Incidência da DRE em regras constitucionais estaduais: $O$ caso Fapesp. Conjur (on line), 18/05/2017. Disponível em

<http://www.conjur.com.br/2017-mai-18/incidencia-dre-regras-constitucionais-estaduais-fapesp> (acesso em 01/05/20).

FALCÃO, Maurin Almeida. O Paradoxo em torno do tributo como alicerce dos direitos à liberdade e à igualdade: uma relação ainda conturbada. Revista do Direito, № 60, p. 124-144, 2020.

FEIJÓ, Paulo Henrique; CARVALHO JR., Jorge Pinto de; RIBEIRO, Carlos Eduardo. Entendendo a contabilidade orçamentária aplicada ao setor público. Brasília: Editora Gestão Pública, 2015.

FEIJÓ, Paulo Henrique. Entendendo a Desvinculação de Receitas de Estados e Municípios (DREM). Grupo Gestão Pública (online). Disponível em <http://www.gestaopublica.com.br/bloggestao-publica/entendendo-a-desvinculacao-de-receitas-de-estados-e-municipios-drem.html> (acesso em 01/05/2020).

FREIRE JÚNIOR, Américo Bedê; DA SILVA Willy Potrich. Analítica e hermenêutica: duas faces de uma mesma solução para a garantia da racionalidade na aplicação do direito. Revista do Direito, no 57, p. 43-62, 2019.

GOMES, Emerson Cesar da Silva. O Direito dos Gastos Públicos no Brasil. São Paulo: Almedina, 2015.

IUDíCIBUS, Sérgio de. Teoria da Contabilidade. 11aㅡ ed. São Paulo: Atlas, 2015.

JUSTEN FILHO, Marçal. Curso de Direito Administrativo. 12ª . São Paulo: Ed. Revista dos Tribunais, 2016

KLEIN, Vinícius; GRANDO, Guilherme. Empresas Estatais e Governança Corporativa. Revista de Direito Empresarial - RDEmp, v. 16, p. 31-46, 2019.

MUSACHIO, Aldo; LAZZARINI, Sergio G. Reinventando o Capitalismo de Estado: o Leviatã nos negócios: Brasil e outros países. São Paulo: Portfolio-Penguin, 2015.

MAXIMILIANO, Carlos. Hermenêutica e Aplicação do Direito. 16 ed. Rio de Janeiro: Forense, 1996.

MOORE, Marc; PETRIN, Martin. Corporate Governance: law, regulation and theory. London: Palgrave, 2017. 
OLIVEIRA, Weder de. Curso de Responsabilidade Fiscal. Belo Horizonte: Fórum, 2ª ed., 2015.

PINHO, José Antonio Gomes de; SACRAMENTO, Ana Rita Silva. Accountability: já podemos traduzila para o português?. Revista de Administração Pública, v. 43, n. 6, p. 1343-1368, 2009.

PINTO, Élida Graziane. Seis vezes DRU: flexibilidade orçamentária ou esvaziamento de direitos sociais?. De jure: Revista Jurídica do Ministério Público do Estado de Minas Gerais, p. 511-537, 2008.

PINTO, Mario Engler. Empresa estatal: Função Econômica e Dilemas Societários. São Paulo: Atlas, 2010.

RODRIGUES, Diogo Luiz Cordeiro. A constitucionalização dos Fundos Especiais: o caso das Procuradorias-Gerais dos Estados e do Distrito Federal. Revista Jurídica da Procuradoria-Geral do Estado do Paraná, Curitiba, n. 8, p. 245-283, 2017. Disponível em $<$ http://www.pge.pr.gov.br/sites/default/arquivos restritos/files/documento/201910/009aconstitucionalizacaodosfundosespeciais2017.pdf> (Acesso em 01/05/2020)

SARMENTO, Daniel; SOUZA NETO, Cláudio. Direito Constitucional - Teoria, História e Métodos de Trabalho. Belo Horizonte: Ed. Fórum, 2012.

SILVEIRA, Alexandre Di Miceli da. Governança corporativa no Brasil e no mundo: teoria e prática. 2. ed. Rio de Janeiro: Elsevier, 2015.

SCAFF, Fernando Facury. Direitos humanos e a desvinculação das receitas da União. Revista de Direito Administrativo, v. 236, 2004. 